\title{
Gastrointestinal Radiation Injury
}

National Cancer Institute

\section{Source}

National Cancer Institute. Gastrointestinal Radiation Injury. NCI Thesaurus. Code C161513.

Radiation injury of the gastrointestinal system. 